\title{
Relevance of Single Step Gastric Aspirate Shake Test in Management of Respiratory Distress Syndrome in Preterm Babies and Neonatal Mortality in Rural Setup
}

\author{
Ranbir S Jaswal ${ }^{1 *}$ and Shikha Verma ${ }^{2}$ \\ ${ }^{1}$ Department of Pediatrics, Dr Rajendra Prasad Government Medical College, India \\ ${ }^{2}$ Government Laboratory, Dr Rajendra Prasad Government Medical College, India \\ *Corresponding author: Ranbir S Jaswal MD, Associate Professor, Department of Pediatrics, Dr. Rajendra Prasad Government Medical College, Kangra \\ at Tanda, Himachal Pradesh- 176002, India
}

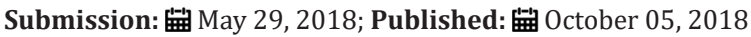

\begin{abstract}
The morbidity and mortality due to preterm births is significant, one of the handicaps of preterm delivery is respiratory distress syndrome (hyaline membrane disease). The timely recognition and referral of these babies from peripheral institutions to tertiary care centers of utmost importance for further management. This study was conducted to highlight the application of this forgotten simple, cheap and sensitive single step gastric aspirate shake test.
\end{abstract}

Keywords: Preterm; Single step gastric aspirate test; Surfactant; Ventilation; Respiratory distress

Abbreviations: CPAP: Continuous Positive Airway Pressure; FFO: Free Flow Oxygen; FLM: Foetal Lung Maturity; GAST: Gastric Aspirate Test; HMD: Hyline Membrane Disease; MV: Mechanical Ventilation; RDS: Respiratory Distress Syndrome

\section{Introduction}

Globally around 15 million babies are born preterm with over all prematurity rate of $5-18 \%$. Prematurity is a leading cause of underfive mortality and constituted about one million deaths in 2015. Cost effective interventions such basic care of infections, warmth, breastfeeding, handling breathing difficulties and good antenatal care can prevent up to $75 \%$ of these deaths. The survival rate is also determined by the socio- economic status of the countries. India tops the list among 10 low income group countries where half of the preterm babies are born prior to 32 weeks of gestation. According to Lancet in 2010, 3519100 preterm were born in India whereas in China 1172300, Nigeria-773600, Pakistan-748100, Bangladesh-424100, Phillippines-348900, Democratic Republic of Congo-34100 and Brazil-279300 preterm babies were born [1]. Respiratory distress syndrome (RDS) previously known as HMD is the major cause of morbidity and mortality in preterm neonates. The R DS occurs in $60-80 \%$ of infants born prior to 28 weeks of gestation and is inversely related to gestational age and birth weight. The risk for development of RDS increases with maternal diabetes, multiple births, cesarean delivery, precipitous delivery, asphyxia, cold stress, and a maternal history of previously affected infants. The risk of RDS is reduced in pregnancies with chronic or pregnancy associated hypertension, maternal heroin use, prolonged rupture of membranes, and antenatal corticosteroid prophylaxis. The deficiency of surfactant which is underlying cause of RDS results in progressive atelectasis, loss of functional residual capacity ends in uneven distribution of ventilation.

The surfactant which reduces the surface tension at air liquid interface in the alveoli is produced by type II alveolar cells in the fetal lungs by 20 weeks of gestation and appears in amniotic fluid by 28-32 weeks. The mature levels of surfactant are present after 35 weeks of gestation [2]. The deficiency of surfactant can be predicted antenatally by measuring the lecithin sphingomyelin (L/S) ratio, phosphatidyl glycerol assay, shake test on amniotic fluids, TDx FLM II (mature lung $>55 \mathrm{mg} / \mathrm{gm}$ ) and lamellar body count (mature lung $>50,000 /$ microliter) and postnatally can be detected by shake test performed on gastric aspirate from newborn [3]. Single step gastric aspirate shake test, a test to determine the surfactant deficiency which is forgotten identity in most institutions specially PHC can be a great help to decrease under five-year morbidity and mortality, without causing much financial burden and technical difficulties to the health personnel. In India most of the deliveries are conducted in rural institutions where management of basic complications like hypothermia, breast feeding and infection control can be carried out but timely diagnosis of RDS in pre-term babies is crucial for referral of these babies to tertiary care centers for further management of RDS. This study was conducted with the purpose to re-establish 
the importance of gastric aspirate shake test in rural health care centers for timely diagnosis and referral of pre-terms with RDS.

\section{Material and Methods}

Seventy-nine preterm neonates (44 male and 35 females) admitted in newborn nursery of tertiary care hospital during May 2014 to April 2015 with gestational age between 28 weeks to 34 weeks were subjected to single step gastric aspirate shake test within first hour of birth. Gastric aspirate samples were obtained within above said period before first feed to the baby or before gastric lavage is performed. Specimens were aspirated with a No. 6 French polyethylene feeding tube and were tested as per following protocol. Firstly, half milliliter $(0.5 \mathrm{ml})$ of normal saline and $1.0 \mathrm{ml}$ of $95 \%$ ethyl alcohol taken in a clean $10 \mathrm{mmX} 110 \mathrm{~mm}$ test tube, to which $0.5 \mathrm{ml}$ of gastric aspirate was added and shaken vigorously for 15 seconds and allowed to settle down for 15 minutes. The surface was inspected for quantum of froth or bubbles. When bubble cover $1 / 3$ rd or less of liquid surface the test interpreted as negative, indicative of high risk of developing RDS. Bubbles covering $1 / 3$ rd to $2 / 3 \mathrm{rd}$ of liquid surface interpreted as intermediate test and occupying $2 / 3$ rd or more of liquid surface interpreted as positive test, suggesting full pulmonary maturity [4]. Diagnosis of RDS was made clinically according to Downe's scoring system [5] and by chest radiograph.

\section{Results}

Table 1: Results of shake test $(n=79)$.

\begin{tabular}{|c|c|c|}
\hline Shake Test Result & Number (n) & Percentage (\%) \\
\hline Positive & 58 & 73.5 \\
\hline Intermediate & 12 & 15.1 \\
\hline
\end{tabular}

\begin{tabular}{|c|c|c|}
\hline Negative & 9 & 11.4 \\
\hline Total & 79 & 100 \\
\hline$(\mathrm{p}=0.04)$ & & \\
\hline
\end{tabular}

Table 2: Relationship between shake test and RDS.

\begin{tabular}{|c|c|c|c|}
\hline Test Result & Total(n) & With RDS & Percentage \% \\
\hline Positive & 58 & 1 & 1.7 \\
\hline Intermediate & 12 & 11 & 91.6 \\
\hline Negative & 9 & 9 & 100 \\
\hline$(p=0.000)$ & & & \\
\hline
\end{tabular}

Results of shake test: Table $1(\mathrm{n}=79)$. Gastric aspirate shake test was done in 79 preterm neonates, nine $(11.4 \%)$ of them had negative test result while $12(15.1 \%)$ and $58(73.5 \%)$ had intermediate and positive test results respectively $(\mathrm{p}=0.04)$ (Table 2$)$. Only $1(1.7 \%)$ out of 58 neonates with positive shake test result developed RDS. All of $9(100 \%)$ neonates with negative shake test developed RDS while $11(91.6 \%)$ out of 12 neonates with intermediate test also developed RDS (Table 3). Proportion of Respiratory Distress Syndrome among newborn was found statistically significantly lower among those who had positive shake test in comparison to those who had shake test either negative or intermediate. ( $p$ value $<0.01$ ) No significant difference was found in proportion of RDS among newborn who had shake test intermediate in comparison to those who had shake test negative. (p value 0.54) (Table 4). In our study results of GAST among preterm infants in predicting occurrence of RDS showed sensitivity-95.23\%, specificity-98.27\%, positive predictive value (PPV)-95.23\% and negative predictive value (NPV)-98.27\% respectively (Table 5).

Table 3: Respiratory distress syndrome among newborn \& Shake test results.

\begin{tabular}{|c|c|c|c|c|}
\hline & & \multicolumn{2}{|c|}{ Respiratory Distress Syndrome n (\%) } & \multirow{2}{*}{ p-value } \\
\hline & & Present (n-21) & Absent (n-58) & \\
\hline \multirow[t]{2}{*}{ Shake Test } & \multirow[b]{2}{*}{ Positive (n-58) } & \multirow[b]{2}{*}{$1(1.7 \%)$} & \multirow[b]{2}{*}{$57(98.3 \%)$} & ${ }^{a}<0.01$ \\
\hline & & & & ${ }^{b}<0.01$ \\
\hline & & (-12) & & c 0.54 \\
\hline & Negative (n-09) & $9(100 \%)$ & 0 & $\mathrm{~d}<0.01$ \\
\hline \multicolumn{5}{|c|}{ 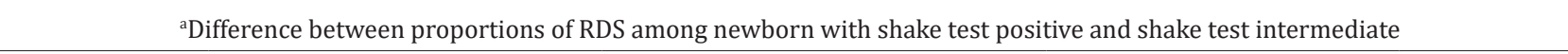 } \\
\hline \multicolumn{5}{|c|}{${ }^{\mathrm{b}}$ Difference between proportions of RDS among newborn with shake test positive and shake test negative } \\
\hline \multicolumn{5}{|c|}{ 'Difference between proportions of RDS among newborn with shake test intermediate and shake test negative } \\
\hline
\end{tabular}


Table 4: Results of GAST in all preterm in diagnosing RDS $(\mathrm{n}=79)$.

\begin{tabular}{|c|c|c|c|}
\hline Cases & $\begin{array}{c}\text { GAST Negative/Inter- } \\
\text { mediate }\end{array}$ & GAST Positive & Total \\
\hline With RDS & 20 & 1 & 21 \\
\hline Without RDS & 1 & 57 & 58 \\
\hline Total & 21 & 58 & 79 \\
\hline
\end{tabular}

Table 5: Intervention in 21 shake test Negative/Intermediate newborn: $(n=21)$.

\begin{tabular}{|c|c|c|}
\hline Interventions & With RDS & Without RDS \\
\hline FFO & - & 1 \\
\hline FFO+CPAP & $10(50 \%)$ & - \\
\hline FFO+CPAP +Surfactant & $7(35 \%)$ & - \\
\hline FFO+CPAP+Surfactant+MV & $3(15 \%)$ & - \\
\hline Total & $20(100 \%)$ & \\
\hline$(\mathrm{p}=.000)$ & & \\
\hline
\end{tabular}

The preterms after birth were assessed using Downe's scoring system and Chest X-ray when possible. Twenty preterms who developed respiratory distress clinically (Downe's score $>4$ ) were given nasal CPAP initially and monitored continuously. Ten out of twenty (50\%) required CPAP as only intervention and subsequently weaning with FFO. Chest X-ray could be done in seven out of twenty and had reticulogranular pattern along with respiratory distress so surfactant (Neosurf (Cipla) $5 \mathrm{ml} / \mathrm{kg}$; strength $27 \mathrm{mg} / \mathrm{ml}$ ) was administered as per protocol for management of RDS. Three out of twenty developed impending respiratory failure so were given surfactant followed by mechanical ventilation (SIMV mode) as they were not maintaining oxygen saturation due to poor respiratory efforts.

\section{Discussion}

Respiratory distress syndrome (RDS) is one of the commonest disorders encountered within first few hours of life and remains one of the major contributors for preterm mortality and morbidity. The deficiency of pulmonary surfactant leads to progressive atelectasis and RDS resulting in respiratory failure and death. Therefore, it is important to have a test to predict surfactant deficiency in prematurely born infants immediately after birth for their best management. Gluck and colleagues [6] correlated the development of RDS in preterm babies by measuring the lecithin and sphingomyelin ratio (L:S ratio) in amniotic fluid. This gold standard invasive and expensive test is not available in developing countries where antenatal care is given in primitive institutions in rural setup. The need for a rapid test prompted numerous assays of the functional and physical characteristics of amniotic fluid resulted in development of the 'shake test' which was still an antenatal and invasive test [7]. The similar shake test from gastric aspirate instead of amniotic fluid (GAST) was performed first time in 1972 to identify immaturity of lungs postnatally [8-
10]. The results of this study suggest that GAST is a safe, technically easy, economical and reliable indicator of pulmonary maturity and hence of the risk of RDS (Table 1). All of $9(100 \%)$ neonates with negative shake test developed RDS while 11(91.6\%) out of 12 neonates with intermediate test developed RDS. Only $1(1.7 \%)$ out of 58 neonates with positive shake test result developed RDS. The usefulness of GAST in predicting RDS is statistically significant with $P$ value 0.000 . The results of present study are similar to the previous observations by various authors in predicting the usefulness of the GAST in the development of RDS. In this study GAST showed sensitivity $95.23 \%$, specificity $98.27 \%$, PPV $95.23 \%$, and NPV 98.27\% (Table-3) similar to the several other studies like Noorishadkam et al. [11], Mohammadi et al. [12], Keerti et al. [13], Gupta et al. [14].

In contrast to this study Mehrpisheh S et al. [15] and Amoa et al. [16] reported large number of false positive results with this test but our study found only $1.7 \%$ false-positive results with no statistical significance. The results from this study and previous studies indicate that the gastric aspirate shake test appears to be a reliable method of excluding RDS as a cause of respiratory distress in the newborn and may be easily performed immediately after delivery. Even before the newborn is symptomatic clinically this test can guide us regarding the status of lung maturity in preterm babies. Hence the test should be routinely done in all newborn who are at high risk for development of RDS for timely referral and management.

\section{Conclusion}

Till today single step gastric aspirate shake test is helpful in predicting respiratory distress syndrome in pre-term babies with increasing numbers of peripheral institutional deliveries. All the medical and paramedical health care works should be trained to perform this test so that timely recognition, management and referral is made for surfactant administration or mechanical ventilation.

\section{References}

1. Blencowe H, Cousens S, Oestergaard M, Chou D, Moller AB, et al. (2010) National, regional and worldwide estimates of preterm birth. The Lancet 379(9832): 2162-2172.

2. Kliegman RM, Stanton BF, Schor NF, St. Geme JW, Behrman RE (2007) Nelson textbook of pediatrics. (19 ${ }^{\text {th }}$ edn), Saunders an imprint of Elsevier 1600 John F. Kennedy Blvd. Philadelphia, USA, pp. 581-582.

3. Cloherty JP, Eichenwald EC, Hasen AR, Stark AR (2012) Manual of neonatal care. In: Lippincott W, Wilkins (Eds.), ( $7^{\text {th }}$ edn), A Wolters Kluwer business, USA, p. 407.

4. Singh M (2010) Care of the newborn. ( $7^{\text {th }}$ edn), Respiratory Disorders: New Delhi Sagar publications, India, p. 283.

5. Singh M (2010) Care of the newborn. ( $7^{\text {th }}$ edn), Respiratory Distress New Delhi Sagar publications, India, p. 277.

6. Gluck L, Kulovich MV, Borer RC, Keidel WN (1977) The interpretation and significance of the lecithin-sphingomyelin ratio in amniotic fluid. Am J Obstet Gynecol 120(1): 142-155.

7. Clements JA, Platzker ACG, Tierney DF, Hobel CJ, Creasy RK, et al. (1972) Assessment of the risk of the respiratory-distress syndrome by a rapid test for surfactant in amniotic fluid. N Eng J Med 286(20): 1077-1081. 
8. Evans JJ (1975) Prediction of respiratory distress syndrome by shake test on newborn gastric aspirate. N Engl J Med 292(21): 1113-1115.

9. Jones MD, Albert R, Sende P (1974) The newborn gastric aspirate. Obstet and gynec 43: 150-152.

10. Cowett RM, Unsworth EJ, Hakanson DO, Williams JR, Oh W (1975) Foam stability test on gastric aspirate and the diagnosis of respiratory distress syndrome. N Engl J Med 293(9): 413-416.

11. Noori Shadkam M, Lookzadeh MH, Taghizadeh M, Golzar A, Noori Shadkam Z (2014) Diagnostic value of gastric shake test for hyaline membrane disease in preterm infant. Iran J Reprod Med 12(7): 487-491.

12. Mohammadi M, Iranpour R, Mohammadizadeh M, Soleymani $B$, Hajiheydari M (2009) Gastric aspirate shake test for predicting of surfactant therapy in premature neonates with hyaline membrane disease. Journal of Isfahan Medical School 27(96): 307-315.
13. Keerti S, Manish S (2015) Prevalence of hyaline membrane disease with special reference to significance of gastric aspirate shake test in preterm infants. European Journal of Biomedical and Pharmaceutical Science 2(5): 381-390.

14. Gupta JM, Morris HM, Fisk GC (1978) Gastric shake test and pharyngeal lecithin/sphingomyelin Ratios in newborn infants. Med J Aust 2(1): 7-8.

15. Mehrpisheh S, Mosayebi Z, Memarian A, Kadivar M, Nariman S, et al. (2015) Evaluation of specificity and sensitivity of gastric aspirate shake test to predict surfactant deficiency in Iranian premature infants. Pregnancy hypertension 5(2): 182-186

16. Amoa AB, Paiva M, Klufio CA (2003) Antepartum prediction of respiratory distress syndrome: a comparison of the shake test, the tap test and the turbidity test. PNG Med J 46(1-2): 32-40.
Creative Commons Attribution 4.0 International License

For possible submissions Click Here

\section{Submit Article}

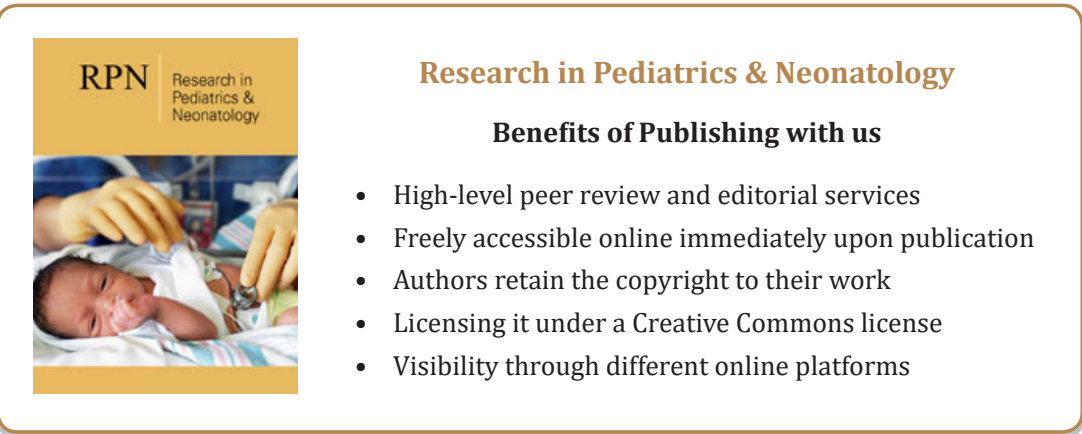

